\title{
Erratum to: Lead in drinking water and human blood in Riyadh City, Saudi Arabia
}

\author{
Abdulaziz M. Al-Othman • Zeid A. Al-Othman • \\ Gaber E. El-Desoky • Mourad A. M. Aboul-Soud • \\ Mohamed A. Habila • John P. Giesy
}

Published online: 6 August 2013

(C) Saudi Society for Geosciences 2013

Erratum to: Arab J Geosci (2013) 6:3103-3109
DOI 10.1007/s12517-012-0551-4

The original version of this article unfortunately contained an error.

In line number 2 of the abstract it states that "blood plas$\boldsymbol{m a}$ " was used. However, this is not correct. The authors would like to point out that "whole blood" was used for the quantification of $\mathrm{Pb}$ in humans.

The online version of the original article can be found at http://dx.doi.org/ 10.1007/s12517-012-0551-4.

\footnotetext{
A. M. Al-Othman

Department of Community Health Sciences,

College of Applied Medical Science, King Saud University,

Riyadh 11433, Saudi Arabia
}

\section{Z. A. Al-Othman • G. E. El-Desoky • M. A. Habila}

Chemistry Department, College of Science, King Saud University,

Riyadh 11451, Saudi Arabia

G. E. El-Desoky • M. A. M. Aboul-Soud

The Biochemistry Department, Faculty of Agriculture,

Cairo University,

Giza 12613, Egypt

M. A. M. Aboul-Soud $(\square) \cdot$ J. P. Giesy

King Saud University,

P.O. BOX 2245, Riyadh 11451, Kingdom of Saudi Arabia

e-mail:maboulsoud@ksu.edu.sa

J. P. Giesy

Department of Veterinary Biomedical Sciences and Toxicology

Centre, University of Saskatchewan,

Saskatoon, SK, Canada

J. P. Giesy

Department of Zoology, Center for Integrative Toxicology,

Michigan State University,

East Lansing, MI, USA 